\title{
METODE OPERASI REVERSE FLOW REACTOR DENGAN UMPAN FLUKTUATIF DALAM PENGOLAHAN EMISI GAS METANA DI STASIUN KOMPRESOR
}

\author{
M. Effendy, Yogi Wibisono Budhi*, Yazid Bindar, dan Subagjo \\ Program Studi Teknik Kimia, Fakultas Teknologi Industri, Institut Teknologi Bandung \\ Jalan Ganesha No. 10 Bandung 40132 \\ Email: Y.Wibisono@che.itb.ac.id
}

\begin{abstract}
Abstrak
Kebocoran gas $\mathrm{CH}_{4}$ dari stasiun kompresor tidak dapat dihindarkan dan ini merupakan salah satu sumber penyebab pemanasan global. Dampak pemanasan global ini dapat dikurangi dengan mengoksidasi gas $\mathrm{CH}_{4}$ menjadi gas $\mathrm{CO}_{2}$. Strategi penangkapan gas $\mathrm{CH}_{4}$ menggunakan exhaust yang terpasang pada bagian atas gedung menyebabkan (1) kadar $\mathrm{CH}_{4}$ yang terdeteksi dalam campuran gas cukup kecil ( $\pm 1 \%$ volume), (2) temperatur gas umpan mendekati temperatur ruangan $\left( \pm 30^{\circ} \mathrm{C}\right)$, (3) konsentrasi gas $\mathrm{CH}_{4}$ akan berperilaku dinamik. Reverse flow reactor (RFR) mempunyai kemampuan untuk mengatasi akibat yang ditimbulkan oleh proses penangkapan gas $\mathrm{CH}_{4}$ di stasiun kompresor dan mempunyai kemampuan secara ototermal. Tujuan penelitian ini adalah mendapatkan metode operasi yang tepat untuk mengatasi gas umpan yang berperilaku dinamik. Model yang dikembangkan mengacu pada persamaan kontinuitas dan konsentrasi gas umpan yang berperilaku dinamik dimodelkan sebagai fungsi step. Model diselesaikan menggunakan software FlexPDE versi 6. Penggunaan switching time (ST) yang tepat dapat mengatasi permasalahan konsentrasi gas umpan yang berperilaku dinamik. Pada ST 50 detik, RFR mampu bekerja secara ototermal dengan nilai akumulasi panas di bagian inert yang berfluktuasi antara 12,4-14,2 kJ. Pada ST 100 detik, panas yang terjebak di dalam reaktor semakin lama semakin meningkat. Penggunaan ST 100 detik memerlukan prosedur operasi tambahan untuk menjaga reaktor agar tidak meleleh dan menjaga reaktor tetap beroperasi secara ototermal.
\end{abstract}

Kata Kunci: Pemanasan global, dinamika konsentrasi, operasi ototermal, pemodelan dan simulasi, reaktor aliran bolak-balik

\begin{abstract}
The leak of $\mathrm{CH}_{4}$ from the compressor stations can not be avoided and it may cause the global warming. The impact of the global warming can be reduced by oxidizing $\mathrm{CH}_{4}$ into $\mathrm{CO}_{2}$. The $\mathrm{CH}_{4}$ capture strategy using the exhaust mounted on the top of the building causes (1) $\mathrm{CH}_{4}$ levels detected in the gas mixture is very small ( $\pm 1 \%$ volume), $(2)$ the feed gas temperature is near the ambient temperature $\left( \pm 30 \mathrm{o}\right.$ C), (3) the $\mathrm{CH}_{4}$ concentration fluctuates over time. The reverse flow reactor (RFR) is a fixed bed reactor, which has the ability to abate the leak of $\mathrm{CH}_{4}$ and has the ability to act as an autothermal reactor. The purpose of this research is to find a proper operation procedure of the fixed bed reactor for the oxidation of lean methane emission via modeling and simulation. The reactor model is based on the continuity equation and the heat balance, while the concentration of the feed gas behavior dynamic and modeled as a step function. The model was solved numerically using the software package FlexPDE version 6. At ST (switching time) 50 seconds, the RFR operates autothermally with heat accumulation in the inert section fluctuating between 12.4 to $14.2 \mathrm{~kJ}$. At ST 100 seconds, the heat trap inside the reactor increases monotonically. The use of ST 100 seconds requires an additional operation procedure to keep the reactor safe.
\end{abstract}

Keywords: Global warming, concentration dynamic, autothermal operation, modeling and simulation, reverse flow reactor

*korespondensi 


\section{Pendahuluan}

Kebocoran gas bumi di stasiun kompresor hampir pasti terjadi. Hal ini dikarenakan komponen utama penyusun gas bumi adalah metana. Metana tergolong molekul yang sangat kecil, sehingga sering terjadi kebocoran pada seal yang digunakan untuk menghubungkan instrumen-instrumen dalam stasiun kompresor. Sumber kebocoran dalam stasiun kompresor berasal dari tiga tempat, yaitu reaksi pembakaran yang tidak sempurna pada mesin kompresor, kebocoran yang terjadi pada peralatan seperti valve dan flange, dan pada instrumen venting kompresor (Hayes, 2004).

Kebocoran gas $\mathrm{CH}_{4}$ dalam satu stasiun kompresor relatif kecil jika dibandingkan dengan gas bumi yang mengalir di dalam jaringan perpipaan transmisi. Rata-rata kebocoran yang terjadi di bawah 0,01\% (Picard, 2002). Kebocoran gas $\mathrm{CH}_{4}$ yang relatif sedikit membutuhkan strategi untuk menangkap kebocoran tersebut. Strategi menangkap gas $\mathrm{CH}_{4}$ yang bocor di stasiun kompresor adalah dengan membangun sebuah gedung yang membentengi stasiun kompresor dan di bagian atas kompresor dipasang exhaust yang berfungsi sebagai alat untuk menghisap kebocoran gas $\mathrm{CH}_{4}$ di dalam gedung stasiun kompresor yang telah bercampur dengan udara (Litto dkk., 2007). Proses seperti ini mengakibatkan, (1) kadar $\mathrm{CH}_{4}$ yang terdeteksi dalam campuran gas cukup kecil ( $\pm 1 \%$ volume), (2) temperatur gas umpan mendekati temperatur ruangan $( \pm 30$ ${ }^{\circ} \mathrm{C}$ ), (3) konsentrasi gas $\mathrm{CH}_{4}$ akan berperilaku dinamik.

Dampak akibat kebocoran gas $\mathrm{CH}_{4}$ pada stasiun kompresor ke lingkungan dapat dikurangi dengan cara mengoksidasi gas $\mathrm{CH}_{4}$ menjadi gas $\mathrm{CO}_{2}$. Oksidasi gas $\mathrm{CH}_{4}$ menjadi $\mathrm{CO}_{2}$ akan mengurangi dampak pemanasan global sebesar $87 \%$. Reaksi oksidasi katalitik gas $\mathrm{CH}_{4}$ menjadi gas $\mathrm{CO}_{2}$ adalah reaksi yang bersifat eksotermis.

Metode operasi aliran bolak-balik yang diterapkan pada reaktor unggun diam katalitik atau reverse flow reactor (RFR) adalah metode yang tepat untuk mengoksidasi gas $\mathrm{CH}_{4}$ menjadi $\mathrm{CO}_{2}$. RFR mempunyai keunggulan dibandingkan reaktor unggun diam katalitik konvensional di dalam hal: (a) kemampuan untuk beroperasi secara ototermal, walaupun $\Delta T$ adiabatik komponen yang dihilangkan cukup kecil (20-30 $\left.{ }^{\circ} \mathrm{C}\right)$ (Matros dan Bunimovich, 1996), (b) mempunyai harga efisiensi termal penukar panas yang lebih besar, sehingga panas hasil reaksi pembakaran gas $\mathrm{CH}_{4}$ dapat dimanfaatkan dengan efisiensi yang tinggi (Barresi dkk., 2007).

Proses pengolahan emisi gas $\mathrm{CH}_{4}$ untuk menjadi komponen gas yang tidak berbahaya terhadap lingkungan menggunakan RFR menyebabkan proses berlangsung secara dinamik. Kondisi dinamik ini diakibatkan oleh dua variabel. Pertama, akibat proses pembalikan arah aliran yang merupakan variabel yang dapat dikendalikan. Kedua, akibat tidak dapatnya mendeteksi titik kebocoran dan pada saat proses penangkapan gas $\mathrm{CH}_{4}$ di stasiun kompresor. Kondisi dinamik ini merupakan variabel yang tidak dapat dikendalikan (Litto dkk., 2007).

Pengaruh dinamik akibat variabel yang kedua akan sangat berpengaruh terhadap proses RFR, khususnya kinerja RFR untuk tetap dapat beroperasi secara ototermal. Kondisi ototermal ini diperoleh karena adanya panas yang terakumulasi pada bagian inert yang digunakan untuk memanaskan gas umpan sampai mencapai kondisi operasi. Kondisi ototermal dalam pengoperasian RFR harus tetap dijaga. Hal ini dimaksudkan agar tidak adanya penambahan emisi yang bersumber dari bahan bakar apabila proses membutuhkan panas.

Strategi untuk menghindari reaktor bersifat non-ototermal adalah dengan membuat suatu prosedur operasi terkait dengan waktu pembalikan arah aliran secara periodik (switching time) terhadap laju akumulasi panas di dalam reaktor khususnya pada bagian inert. Laju akumulasi panas ini dapat memperlihatkan reaktor akan padam (bersifat non-ototermal) atau reaktor akan meleleh.

Tujuan penelitian ini adalah untuk mengembangkan prosedur operasi yang tepat (switching time) sehingga mampu mengatasi dinamika konsentrasi gas umpan.

\section{Tinjauan Pustaka}

Oksidasi gas $\mathrm{CH}_{4}$ menggunakan reaktor unggun tetap dapat dioperasikan secara ototermal. Gambar 1 (a) menunjukkan skema oksidasi gas $\mathrm{CH}_{4}$ secara konvensional. Gambar 1 (b) menunjukkan skema oksidasi gas $\mathrm{CH}_{4}$ menggunakan RFR (Baressi dkk., 2007).

Jika $\Delta T_{p}$ adalah kenaikan temperatur yang dibutuhkan untuk membawa umpan menuju ke kondisi temperature optimum 


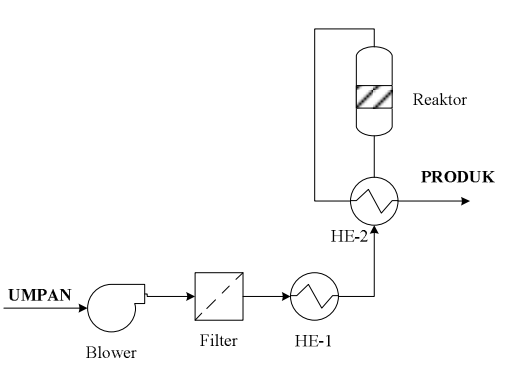

(a) Mode steady state operation

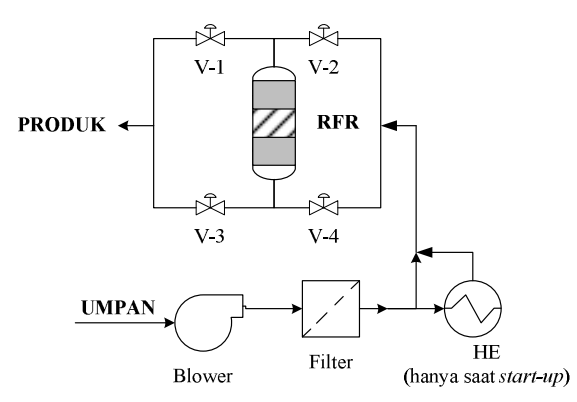

(b) Mode reaktor aliran bolak-balik

\section{Gambar 1. Skema unit pengolahan campuran udara dan $\mathrm{CH}_{4}$, dengan proses oksidasi katalitik (Baressi dkk., 2007)}

reaktor dan $\Delta T_{a d}$ adalah kenaikan temperatur umpan pada reaktor yang beroperasi secara adiabatik, kondisi ototermal dapat tercapai pada saat $\Delta T_{p}$ lebih rendah dari panas yang bisa dimanfaatkan kembali oleh unit pengambil panas, atau dapat dinyatakan dalam persamaan matematis sebagai berikut:

$$
\Delta T_{a d}>\Delta T_{p} \frac{1-\eta}{\eta}
$$

di mana $\eta$ adalah efisiensi dari proses pengambilan panas yang terjadi di dalam proses oksidasi gas $\mathrm{CH}_{4}$, merupakan perbandingan antara panas yang bisa diambil di alat penukar panas Gambar 1(a) atau panas yang bisa digunakan untuk memanaskan umpan Gambar 1(b) dengan jumlah $\Delta H_{\text {reaksi }}$ dan $\Delta T_{p}$.

Baressi dkk. (2007) menyatakan bahwa harga $\eta$ dapat digunakan sebagai acuan awal untuk menentukan kemampuan sistem beroperasi secarta ototermal. Pada saat oksidasi gas $\mathrm{CH}_{4}$ menggunakan reaktor unggun tetap yang beroperasi secara tunak (Gambar 1a), alat penukar panas yang terdapat dalam sistem akan bertindak sebagai recuperative heat exchanger dan memiliki nilai $\eta \approx 70 \%$. Harga $\eta$ yang lebih besar dapat dicapai jika alat penukar panas bertindak sebagai regenerative heat exchanger. Kondisi ini dapat diperoleh pada saat oksidasi gas $\mathrm{CH}_{4}$ menggunakan RFR, yaitu menunjukkan nilai $\eta \approx 95 \%$.

\section{Metodologi}

Penelitian ini difokuskan pada pengaruh switching time tehadap kinerja reaktor secara ototermal akibat dinamika konsentrasi gas umpan. Berbagai variasi ST digunakan dan model matematika digunakan untuk mensimulasikan kinerja reaktor. Model matematika menggunakan persamaan massa dan energi untuk menghasilkan persamaan diferensial parsial. Penyelesaian persamaan diferensial dilakukan menggunakan metode numerik finite element dengan perangkat lunak FlekPDE versi 6.

\section{Model matematik}

Suku akumulasi perlu dilibatkan dalam persamaan matematika karena reaktor beroperasi secara tak tunak akibat pembalikan arah aliran yang dilakukan secara periodik. Kapasitas panas volumetrik dari padatan mempunyai nilai orde tiga kali lipat dibandingkan fasa gas. Ini dilakukan agar akumulasi panas di dalam fasa gas dapat tercakup dari model yang sederhana. Secara prinsip, dalam reaktor unggun diam pergerakan fluida di dalam reaktor didominasi oleh pergerakan gas di sepanjang reaktor. Namun, dalam model matematika pada perpindahan energi, suku dispersi panas perlu dilibatkan karena pada kenyataannya reaktor bersifat non-isotermal.

Suku persamaan laju reaksi menggunakan dasar reaksi global karena oksidasi adalah reaksi yang sangat cepat. Persamaan kontinuitas untuk neraca massa menggunakan model pseudohomogeneous satu dimensi. Hal ini didasarkan pada asumsi tidak ada perpindahan massa antara fasa gas dan fasa padatan. Sedangkan neraca energi menggunakan model heterogeneous satu dimensi. Persamaan 2 sampai 6 menunjukkan model matematika untuk RFR. 
Neraca energi untuk fasa gas:

$$
\left(\varepsilon_{\text {unggun }} C_{p, g} \rho_{g}\right) \frac{\partial T_{g}}{\partial t}=-\left(u_{s}(t) C_{p, g} \rho_{g}\right) \frac{\partial T_{g}}{\partial z}-h_{s} a_{v}\left(T_{g}-T_{s}\right)-\frac{4 U_{w}}{d_{\text {tube-in }}}\left(T_{g}-T_{\text {udara }}\right)
$$

Kondisi batas:

$\lambda_{\text {eff }} \frac{d T_{g}}{d z}=\rho_{g} C_{p, g} u_{s, g}\left(T_{g}-T_{g}^{0}\right)$

pada $x=0$, untuk aliran ke kanan; pada $x=x L$, untuk aliran ke kiri.

Neraca energi untuk fasa padatan:

$\left(\varepsilon_{\text {katalis }} \varepsilon_{\text {unggun }} C_{p, g} \rho_{g}+\left(1-\varepsilon_{\text {unggun }}\right) C_{p, s} \rho_{s}\right) \frac{\partial T_{s}}{\partial t}=k_{e f f} \frac{\partial^{2} T_{s}}{\partial z^{2}}+h_{s} a_{v}\left(T_{g}-T_{s}\right)+\Delta H_{r} r_{C H_{4}}$

Kondisi batas:

$\frac{d T_{s}}{d z}=0$

$$
\text { pada } \mathrm{x}=0 \text { dan } \mathrm{x}=\mathrm{L}
$$

Neraca massa:

$\frac{\partial C_{\mathrm{CH}_{4}}}{\partial t}=-u_{z}(t) \frac{\partial C_{\mathrm{CH}_{4}}}{\partial z}-r_{\mathrm{CH}_{4}}$

Kondisi batas:

$\mathrm{C}_{\mathrm{CH}_{4}}=\mathrm{C}_{\mathrm{CH}_{4}}^{0}$

pada $\mathrm{x}=0$, untuk aliran ke kanan; pada $\mathrm{x}=\mathrm{L}$, untuk aliran ke kiri.

Persamaan laju reaksi untuk reaksi oksidasi $\mathrm{CH}_{4}$ menjadi $\mathrm{CO}_{2}$ mengikuti persamaan laju reaksi orde satu:

$r_{\mathrm{CH}_{4}}=k_{0} \exp \left[\frac{-E_{a}}{R T}\right]\left(C_{\mathrm{CH}_{4}}\right)^{n}$

Model dinamik konsentrasi gas umpan menggunakan fungsi step. Model fungsi step ditunjukkan pada Gambar 2. Amplitudo dinamika konsentrasi gas umpan sebesar $0,5 \%$ dengan frekuensi 10 detik.

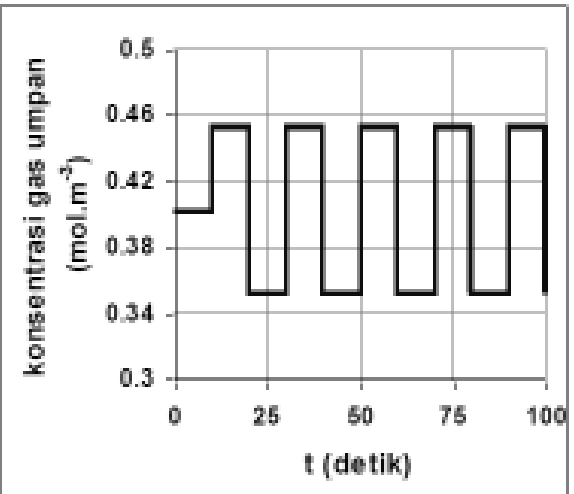

Gambar 2. Dinamika konsentrasi gas umpan fungsi step.
Tabel 2 menunjukkan parameter operasi dan sifat fisik yang digunakan untuk menyelesaikan model matematik yang telah disusun berdasarkan persamaan kontinuitas.

\begin{tabular}{|c|c|}
\hline Kuantitas & Nilai \\
\hline \multicolumn{2}{|l|}{ Kondisi operasi } \\
\hline Laju volumetrik gas umpan, $Q_{g}$ & $1,4 \mathrm{~m}^{3} / \mathrm{s}$ \\
\hline Temperatur gas umpan, $T_{g}^{0}$ & $303.15 \mathrm{~K}\left(30^{\circ} \mathrm{C}\right)$ \\
\hline Fraksi mol metana di gas umpan & 0.01 \\
\hline $\begin{array}{l}\text { Laju alir gas umpan, } U_{s} \\
\text { Reactor }\end{array}$ & $0.7 \mathrm{~m} / \mathrm{s}$ \\
\hline Diameter, $\mathrm{d}$ & $0.027 \mathrm{~m}$ \\
\hline Panjang unggun katalis, $\mathrm{L}_{\mathrm{c}}$ & $2 \times 0.03 \mathrm{~m}$ \\
\hline Panjang unggun inert, $\mathrm{L}_{\mathrm{i}}$ & $2 \times 0.1 \mathrm{~m}$ \\
\hline Switching time, & \\
\hline$t_{s}$ & $\begin{array}{l}20 / / 50 / 100 / 150 / \\
200 / 240 \mathrm{~s}\end{array}$ \\
\hline Fraksi kosong unggun, $\varepsilon_{\text {gas }}$ & 0.3 \\
\hline Fraksi volumetrik katalis & 0.451 \\
\hline Koefisien perpindahan panas reaktor & $131 \mathrm{~W} / \mathrm{m}^{2} \cdot \mathrm{K}$ \\
\hline Faktor pre-exponential, $\mathrm{k}_{0}$ & $\begin{array}{l}\text { (a) } 1.61 \times 10^{7} \\
\mathrm{~mol}^{0.19} / \mathrm{m}^{0.57} . \mathrm{s}\end{array}$ \\
\hline $\begin{array}{l}\text { Energi aktifasi, } E_{a} \\
\text { Orde reaksi, n }\end{array}$ & $\begin{array}{l}\text { (a) } 142,4 \mathrm{~J} / \mathrm{mol} \\
\text { (a) } 0.81\end{array}$ \\
\hline \multicolumn{2}{|c|}{${ }^{\mathrm{a}}$ Digunakan oleh Gosiewski dkk. (2007) } \\
\hline \multicolumn{2}{|l|}{ Sifat fisik katalis } \\
\hline Massa jenis, $\rho_{\text {solid }, c}$ & $1541 \mathrm{~kg} / \mathrm{m}^{3}$ \\
\hline Kapasitas panas, $C_{p, c}$ & $836 \mathrm{~J} / \mathrm{kg} . \mathrm{K}$ \\
\hline Konduktifitas panas, $\lambda_{c}$ & $5.51 \mathrm{~W} / \mathrm{m} . \mathrm{K}$ \\
\hline \multicolumn{2}{|l|}{$\underline{\text { Sifat fisik inert }}$} \\
\hline Massa jenis, $\rho_{\text {solid }, i}$ & $2800 \mathrm{~kg} / \mathrm{m}^{3}$ \\
\hline Kapasitas panas, $C_{p, i}$ & $920 \mathrm{~J} / \mathrm{kg} . \mathrm{K}$ \\
\hline Konduktifitas panas, $\lambda_{i}$ & $5.51 \mathrm{~W} / \mathrm{m} . \mathrm{K}$ \\
\hline
\end{tabular}

Tabel 2. Parameter operasi dan sifat fisik

Prosedur operasi

Reaksi dapat berlangsung pada temperatur operasi. Untuk mencapai kondisi 
yang diinginkan langkah-langkah yang dilakukan adalah sebagai berikut:

1. Reaktor dipanaskan hingga temperatur $773 \mathrm{~K}$ di sepanjang reaktor.

2. Campuran gas $\mathrm{CH}_{4}$ (konsentrasi gas $\mathrm{CH}_{4}$ $1 \%$ pada temperatur $773 \mathrm{~K}$ ) dalam udara dialirkan ke dalam reaktor. Aliran dibolakbalik pada switching time tertentu selama 1200 detik.

3. Temperatur gas umpan diturunkan menjadi $303 \mathrm{~K}$ dan dialirkan ke dalam reaktor dan aliran dibolak-balik pada switching time tertentu selama 1200 detik.

4. Dinamika konsentrasi gas umpan dilakukan pada berbagai variasi switching time selama 1200 detik.

5. Langkah 1-4 diulang dengan variasi switching time.

\section{Hasil dan Pembahasan}

Kemampuan reaktor bekerja secara ototermal sangat dipengaruhi oleh kemampuan inert untuk menyimpan panas. Kemampuan inert dalam menyimpan panas dipengaruhi oleh parameter desain seperti: bahan material inert, panjang reaktor, porositas unggun, dan juga parameter operasi seperti konsentrasi umpan, laju alir gas, dan frekuensi ubah (switching time) aliran (Salinger dan Eigenberger, 1996). Pengaruh parameter desain tidak dikaji dalam penelitian kali ini.

Hasil simulasi yang diperoleh untuk mengkaji keterkaitan parameter operasi konsentrasi umpan yang berperilaku dinamik dengan switching time terhadap kinerja reaktor disajikan pada Gambar 3. Pada berbagai variasi switching time yang dilakukan (50, 100, dan 150 detik), metana yang terkonversi sebesar 100\%. Ini disebabkan panas yang tersimpan di bagian inert masih mampu memanaskan gas umpan sampai mencapai temperatur operasi (873 K) selama selang waktu 1200 detik. Kemampuan reaktor bekerja secara ototermal dalam waktu yang lama dapat dilihat dari profil akumulasi panas tiap siklus pada bagian inert reaktor.

Gambar 3 menunjukkan hubungan akumulasi panas di bagian inert tiap siklus untuk berbagai variasi switching time. Pada siklus 1, akumulasi panas untuk ketiga variasi ST mempunyai perbedaan nilai. Nilai akumulasi panas yang berbeda disebabkan oleh perbedaan ST yang diterapkan pada setiap langkah-langkah prosedur operasi.

Pada ST 50 detik, pengaruh dinamika konsentrasi gas umpan tidak berpengaruh terhadap kemampuan reaktor bekerja secara ototermal. Akumulasi panas di bagian inert hanya berperilaku dinamik, namun tidak akan pernah mengalami kenaikan ataupun penurunan. Nilai akumulasi panas yang berfluktuasi antara 12,4-14,2 kJ sudah cukup mampu untuk memanaskan gas umpan sampai mencapai temperatur operasi. Hal ini ditandai dengan konversi metana yang maksimum, yaitu 100\%.

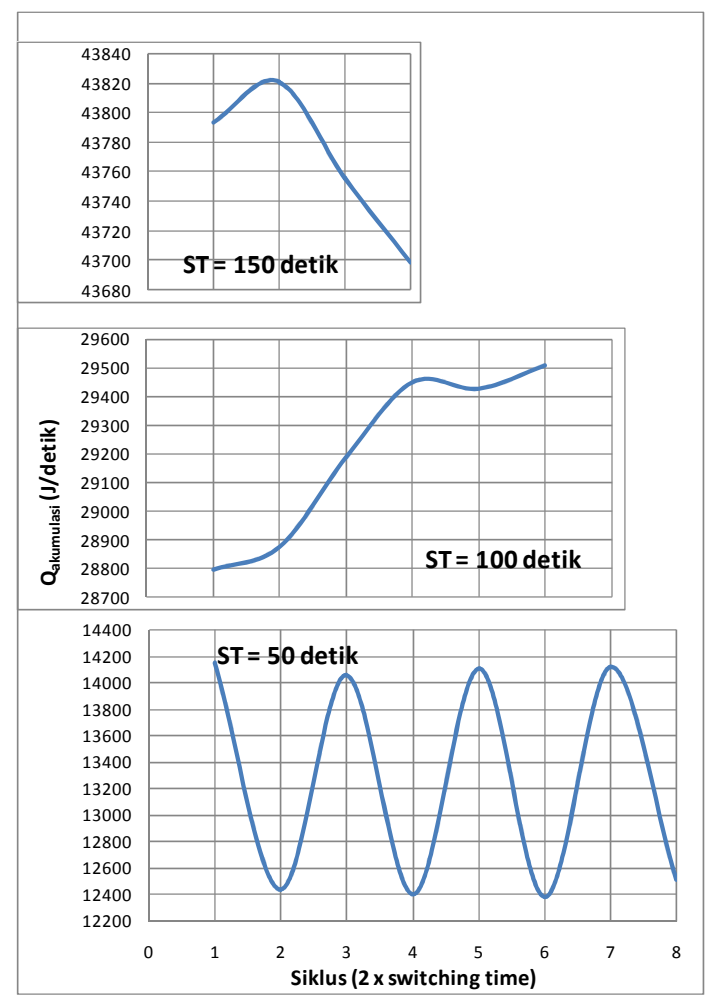

Gambar 3. Akumulasi panas di bagian inert tiap siklus pada berbagai variasi switching time

Pada ST 100 detik, akumulasi panas di bagian inert terus meningkat seiring bertambahnya waktu. Peningkatan nilai akumulasi panas yang terus menerus akan menyebabkan reaktor tidak mampu lagi menahan panas. Maka, untuk prosedur operasi ST 100 detik dengan dinamika konsentrasi gas umpan fungsi step (Amplitudo $0,5 \%$ dan frekuensi 10 detik) reaktor akan mengalami melting. Melting dapat dihindari dengan cara membuat suatu prosedur tambahan untuk mengambil sebagian panas dari reaktor. Prosedur tambahan ini meliputi bagaimana, di mana, dan kapan panas di reaktor harus diambil.

Pada ST 150 detik, akumulasi panas di bagian inert akan mengalami penurunan seiring bertambahnya waktu. Penurunan nilai 
akumulasi panas yang terus menerus akan menyebabkan reaktor padam (reaktor bersifat non-ototermal). Hal ini disebabkan waktu pembalikan arah aliran terlalu lama. Waktu pembalikan arah aliran yang terlalu lama mengakibatkan panas yang diinginkan tersimpan pada bagian inert akan terbawa keluar bersama-sama dengan aliran massa. Akibatnya, seiring bertambahnya waktu akumulasi panas pada bagian inert tidak cukup besar untuk memanaskan gas umpan sampai mencapai temperatur operasi.

\section{Kesimpulan}

Reverse flow reactor mempunyai kemampuan yang andal untuk mengatasi konsentrasi gas umpan yang berperilaku dinamik. Penggunaan switching time yang tepat dapat mengatasi permasalahan konsentrasi gas umpan yang berperilaku dinamik (terlihat pada penggunaan ST 50 detik). Selain itu, $\Delta \mathrm{T}$ adiabatis pada reaksi oksidasi $\mathrm{CH}_{4}$ yang cukup besar $\left(200{ }^{\circ} \mathrm{C}\right.$ pada konsentrasi gas $\mathrm{CH}_{4} 1 \%$ ) mempunyai peluang memanfaatkan panasnya sebagai sumber energi termal. Hal tersebut dapat terlihat pada saat penggunaan ST 100 detik. Akumulasi panas yang terus meningkat di reaktor akan menyebabkan kerugian, panas tersebut harus diambil dan dapat digunakan sebagai sumber energi termal.

\section{Ucapan Terima Kasih}

Penulis menyampaikan terima kasih kepada Ikatan Alumni Institut Teknologi Bandung (IA-ITB) yang telah memberikan bantuan dana penelitian dalam proyek Riset Internasional yang berjudul New Alternative Thermal Energy Production While Reducing Greenhouse Gas Emission from Coal Mine Flue Gas Using a Novel Technology of Reverse Flow Reactor untuk tahun 2008/2009.

\section{Daftar Notasi}

$$
\begin{array}{ll}
\mathrm{r} & =\text { laju reaksi, } \mathrm{mol} /\left(\mathrm{m}^{3} . \mathrm{s}\right) \\
\mathrm{R} & =\text { konstanta gas, } \mathrm{cal} /(\mathrm{gmol} \mathrm{K}) \\
\mathrm{T} & =\text { suhu operasi, } \mathrm{K}
\end{array}
$$

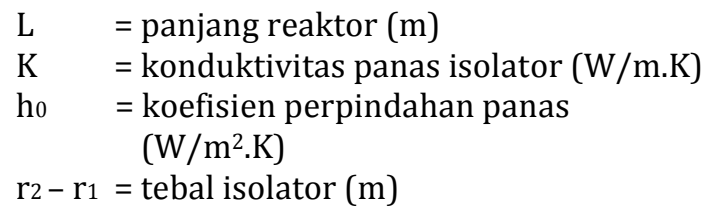

\section{Daftar Pustaka}

Barresi, A. A.; Baldi, G.; Fissore, D., Forced Unsteady-State Reactors as Efficient Devices for Integrated Processes: Case Histories and New Perspectives, Industrial and Engineering Chemistry Research, 2007, Vol. 46(25), 86938700 .

Gosiewski, K.; Matros, Y. Sh.; Warmuzinski, K.; Jaschik, M.; Tanczyk, M., Homogeneous vs. catalytic combustion of lean methane-air mixtures in reverse-flow reactor, Chemical Engineering Science, 2007, Vol. 63(20), 50105019.

Hayes, R. E., Catalytic solutions for fugitive methane emissions in the oil and gas sector, Chemical Engineering Science, 2004, Vol. 59(19), 4073-4080.

Litto, R.; Hayes, R. E.; Liu, B., Capturing fugitive methane emissions from natural gas compressor buildings, Journal of Environmental Management, Vol. 84(3), 2007.

Matros, Y. S.; Bunimovich, G. A., Reverse flow operation in fixed bed catalytic reactor, Catalysis Reviews, 1996, Vol. 38(1), 1-68.

Picard, D., Fugitive Emission from oil and natural gas activities, Clearstone Engineering Ltd., 2002, http://www.ipcc-nggip.iges.or.jp (akses Oktober 2007).

Salinger, A. G.; Eigenberger, G., The direct calculation of periodic states of the reverse flow reactor-I. Methodology and propane combustion results, Chemical Engineering Science, 1996, Vol. 51(21), 4903-4913. 